\title{
Carriership of two copies of C9orf72 hexanucleotide repeat intermediate-length alleles is a risk factor for ALS in the Finnish population
}

\author{
Karri Kaivola ${ }^{1,2^{*}} \mathbb{0}$, Samuli J. Salmi ${ }^{1,2}$, Lilja Jansson ${ }^{1,2}$, Jyrki Launes ${ }^{3}$ (D) Laura Hokkanen ${ }^{3}$, Anna-Kaisa Niemi ${ }^{4,5,6}$, \\ Kari Majamaa ${ }^{4,5}$, Jari Lahti ${ }^{3}$ C, Johan G. Eriksson ${ }^{7,8,9}$, Timo Strandberg ${ }^{10,11}$, Hannu Laaksovirta ${ }^{1,2+}$ \\ and Pentti J.Tienari ${ }^{1,2+}$
}

\begin{abstract}
The hexanucleotide repeat expansion in intron 1 of the C9orf72 gene causes amyotrophic lateral sclerosis (ALS) and frontotemporal dementia. In addition to the effects of the pathogenic expansion, a role of intermediate-length alleles has been suggested in ALS, corticobasal degeneration and Parkinson's disease. Due to the rarity of intermediatelength alleles with over 20 repeats and the geographical variability in their frequency, large studies that account for population stratification are needed to elucidate their effects. To this aim, we used repeat-primed PCR and confirmatory PCR assays to determine the C9orf72 repeat allele lengths in 705 ALS patients and 3958 controls from Finland. After exclusion of expansion carriers (25.5\% of the ALS patients and $0.2 \%$ of the controls), we compared the frequency of intermediate-length allele carriers of $525 \mathrm{ALS}$ cases and 3950 controls using several intermediate-length allele thresholds (7-45, 17-45, 21-45, 24-45 and 24-30). The carriership of an intermediate-length allele did not associate with ALS (Fisher's test, all $p \geq 0.15$ ) nor was there any association with survival ( $p \geq 0.33$ ), when we divided our control group into three age groups (18-65, 66-84 and 85-105 years). Carriership of two intermediate-length alleles was associated with ALS, when the longer allele was $\geq 17$ repeats $(p=0.002$, OR $5.3295 \% \mathrm{Cl} 2.02-14.05)$ or $\geq 21$ repeats ( $p=0.00016$, OR $15.2195 \% \mathrm{Cl} 3.79-61.0)$. Our results show that intermediate-length alleles are a risk factor of ALS when present in both alleles, whereas carrying just one intermediate-length allele was not associated with ALS or survival.
\end{abstract}

Keywords: ALS, C9orf72, Intermediate repeats, Case-control analysis, Aging

\section{Introduction}

The C9orf72 hexanucleotide repeat expansion is the most common genetic cause of amyotrophic lateral sclerosis (ALS) and frontotemporal dementia (FTD) in

\footnotetext{
*Correspondence: karri.kaivola@helsinki.fi

${ }^{\dagger}$ Hannu Laaksovirta and Pentti J. Tienari have contributed equally to this work

${ }^{1}$ Translational Immunology, Research Programs Unit, University of Helsinki, Helsinki, Finland
}

Full list of author information is available at the end of the article populations of European descent [7, 16, 21]. Pathological expansions are usually hundreds to thousands of repeats in length $[2,25]$ and the expansion can exhibit somatic mosaicism [2]. The minimum pathogenic repeat length is unknown, but the threshold of 30 repeats has been commonly used. This threshold might be underestimated since we recently found that about $0.4 \%$ of aged Finns carried 30-45 repeat alleles and these individuals had no apparent increase in the frequency of neurodegenerative or psychiatric diseases [13]. original author(s) and the source, provide a link to the Creative Commons licence, and indicate if changes were made. The images or other third party material in this article are included in the article's Creative Commons licence, unless indicated otherwise in a credit line to the material. If material is not included in the article's Creative Commons licence and your intended use is not permitted by statutory regulation or exceeds the permitted use, you will need to obtain permission directly from the copyright holder. To view a copy of this licence, visit http://creativecommons.org/licenses/by/4.0/. The Creative Commons Public Domain Dedication waiver (http://creativeco mmons.org/publicdomain/zero/1.0/) applies to the data made available in this article, unless otherwise stated in a credit line to the data. 
There are contradictory reports on the effects of intermediate-length alleles under 30 repeats. For example, C9orf72 intermediate-length alleles were reported to be associated with a higher risk of neuropsychiatric symptoms but not directly with various neurodegenerative diseases including ALS [18]. However, two recent large meta-analyses found an association between ALS and 24-30 repeat alleles [5, 12]. The latter study also showed a different frequency of the repeats between the northern and southern European populations [12]. The comparison of different studies on the effects of intermediate-length alleles is complicated by the varying intermediate-length allele thresholds. The different thresholds have been justified in many ways, e.g. association with the same risk haplotype as expansions ( $\geq 7$ repeats) [24], effects on DNA methylation and gene expression (7-24 and 17-29 repeats) [3, 9] and associations with neurodegenerative diseases (e.g. 17-30, 20-22, 20-30, 24-30) [3, $10,12,20]$.

Here, we assessed the length of C9orf72 hexanucleotide repeat alleles in 705 ALS patients and 3958 controls, tested their association with ALS and effect on survival in controls using several intermediate-length allele thresholds.

\section{Materials and methods Cohorts}

We assessed the length of $C 9$ orf 72 hexanucleotide repeat alleles in 773 ALS cases, 405 of whom were included in a previous genome-wide association study and in the discovery study of $C 9$ orf $72[15,21]$. The $C 9$ orf 72 repeat alleles were newly genotyped in 2019-2020 for all samples. There were 177 (23\%) familial ALS cases and 596 apparently sporadic cases. The patients' mean age-ofonset was 58 years and $51 \%$ were females. The patients were recruited at the Department of Neurology, Helsinki University Hospital, that receives referrals from neurologists throughout Finland. After exclusion of ALS cases with non-Finnish ancestry $(n=15)$ on the basis of patients' self-reported birth-places and related individuals ( $n=46,>0.185$ proportion identity-by-descent), there were 712 ALS cases remaining for the present study.

Our control group consisted of individuals from six cohorts. We have previously determined the C9orf72 hexanucleotide repeat lengths in four cohorts and the cohort descriptions have been previously published [13]. In brief, the Vantaa 85+ study consists of 553 individuals of at least 85 years of age, who were living in the city of Vantaa, Finland on April 1st 1991 (DNA available in 486). The Helsinki Birth Cohort Study (HBCS) originally consisted of 8760 individuals born in Helsinki in 19341944, and a random subsample of 2003 individuals was neurologically assessed and underwent DNA extraction in 2001 (DNA was available in 1651 individuals for the present study). The Helsinki Businessmen study (HBS) included men with high socioeconomic status who were born in 1919-1934 and in 2002-2003, 672 individuals who lived at home were randomly selected for analyses (DNA was available in 666). The DEBATE study was originally a random sample of 4800 individuals from Helsinki out of whom 400 home-living individuals with stable cardiovascular disease were randomly selected for further studies in 2000 (DNA was available for 375). We excluded one individual diagnosed with ALS from these cohorts, which decreased the number of controls from the original 3142 to 3141.

The first of the new control cohorts is the PLASTICITY cohort [11], which consists of originally 1196 individuals born in 1971-74 in the Helsinki metropolitan area who had at least one predefined pre- or perinatal risk factor (e.g. birth weight $\leq 2000$ g, Apgar score $<7$, respiratory distress syndrome, diabetic mother, septic infection). At the age of 40 years, a survey using a mailed questionnaire about neurodevelopmental symptoms was conducted and 509 subjects responded (DNA available in 433). The second new control cohort includes 400 healthy blood donors aged 18-65 years at the time of study participation $[17,19]$, who were recruited in Northern Ostrobothnia $(n=102)$, Kainuu $(n=85)$, North Savo $(n=61)$, Pirkanmaa $(\mathrm{n}=152)$ (DNA available in 400$)$.

\section{Genotyping}

We extracted DNA using standard methods from peripheral blood leukocytes ( 5 cohorts) or saliva (PLASTICITY cohort). We assessed the C9orf 72 hexanucleotide repeat alleles as previously described [21] with minor modifications [13]. In brief, for all samples, we first assessed repeat lengths using repeat-primed PCR (RP-PCR) followed by capillary electrophoresis and the results were visualized using the GeneMapper software v6 (ThermoFisher). Then, for samples with a putative expansion (including all samples with $\geq 20$ repeats) or unclear zygosity, we performed over-the-repeat PCR. Samples that showed the typical saw tooth pattern in RP-PCR and did not produce longer amplicon in over-the-repeat PCR were categorized as expansions. The longest non-expanded (amplifiable) discrete allele we could detect was 45 repeats, and we used it as the expansion threshold [13]. Examples of RP-PCR capillary electrophoresis chromatograms and over-the-repeat PCR analyses are in Additional file 1: Supplementary Figure 1.

We used rs3849942 allele A as a marker for the C9orf 72 risk haplotype [2]. Samples from HBS $(n=669)$, PLASTICITY $(\mathrm{n}=444)$ and DEBATE $(\mathrm{n}=360)$ cohorts were genotyped with Illumina Global Screening Array 24v2-3, 
Vantaa85+ $(\mathrm{n}=512)$ with Illumina HumanCNV370 array, HBCS $(\mathrm{n}=1643)$ with Illumina $610 \mathrm{k}$ array and ALS cases $(n=803)$ with Affymetrix Axiom custom SNP array. Genotyping data underwent standard per-sample and per-variant quality control steps [1].

\section{Statistics}

We used Fisher's exact test to test for differences in the frequency of intermediate-length allele carriers between individuals with ALS and controls. We used the Cochran-Armitage trend test to estimate linear trends between the frequency of intermediate-length allele carriers and different age groups as implemented in the CATT package (Du and Hao 2017) in $\mathrm{R}$ version 3.5.2 ( $\mathrm{R}$ Core Team 2017). Since there is no established threshold for intermediate-length alleles, in the main analysis we tested several thresholds with decreasing allele frequency: (1) 7-45 repeats, (2) 17-45 repeats, (3) 21-45 repeats, (4) 24-45 repeats and (5) 24-30 repeats. Since it can be assumed that the effect of the expansion overshadows any possible effects of an intermediate-length allele, we excluded all expansion carriers from the main analyses.

We calculated the statistical power of our study using the genpwr package (Moore, Jacobson 2019) as implemented in $\mathrm{R}$ version 3.5.2 (Additional file 1: Supplementary Table 1).

\section{Results}

C9orf72 hexanucleotide repeat expansion and intermediate-length alleles in the Finnish cohorts

We successfully genotyped 705/712 (99.0\%) of the ALS patients and 3958/3993 (99.1\%) of the controls. There were $180(25.5 \%)$ ALS cases and $8(0.20 \%)$ controls who carried the C9orf 72 hexanucleotide repeat expansion and they were excluded from the main analyses leaving 525 ALS cases and 3950 controls.

The demographic details and C9orf72 intermediatelength allele and expansion carrier frequencies as well as C9orf72 risk haplotype tagging SNP frequency in each control cohort are in Additional file 1: Supplementary Table 2.

\section{Association of C9orf72 hexanucleotide repeat intermediate-length alleles with ALS}

We did not observe any significant differences in the frequencies of the intermediate-length allele carriers between ALS patients and controls (all $p \geq 0.15$ ) (Table 1). The results did not markedly change when the 188 individuals with an expansion were included (all $p \geq 0.31$, Additional file 1: Supplementary Table 3). All intermediate-length allele carrier frequencies (without predefined thresholds) in cases and controls are presented in Additional file 1: Supplementary Table 4.
We made an additional analysis in individuals with two intermediate-length alleles. There was a statistically significant difference in the frequency of individuals with any two copies of intermediate-length alleles (7-45 repeats) between ALS (26/525, 5.0\%) and controls $(104 / 3950,2.6 \%)(p=0.005, \mathrm{OR}=1.93$ [1.19-3.02]). Table 2 illustrates the risk of ALS in individuals with two copies of the intermediate-length alleles stratified by the length of the longer allele. In this analysis the increased risk is observed when the longer allele is $\geq 17$ repeats (Table 2). Our data is not powered to pinpoint an exact threshold of increased risk, all genotypes of the cases and controls with two copies of intermediate-length alleles are shown in Additional file 1: Supplementary Table 5. Most individuals with two intermediate-length alleles were compound heterozygotes, i.e. they had two different intermediate-length alleles. (62\% of ALS cases and $66 \%$ of the controls, Additional file 1: Supplementary Table 5).

\section{C9orf72 risk haplotype}

The haplotype tagging SNP rs3849942 was successfully genotyped in 683 ALS cases and 3178 controls. After the exclusion of expansion carriers, the frequency of rs3849942 (A) carriers (marker of the risk haplotype) was $995 / 3172(31.4 \%)$ in the controls and $182 / 505$ (36.0\%) in ALS cases $(p=0.041, \mathrm{OR}=1.23$ [1.01-1.50], $\mathrm{X}^{2}$ test). The difference was largely driven by the higher number of individuals homozygous for the rs3849942 (A) allele in ALS cases than in controls (Table 3). The odds ratio of homozygosity for rs3849942 (A) was 1.89 (95\% CI 1.20-2.99, $p=0.018$ ). This association was lost, when individuals with intermediate-length alleles were excluded as there were one ALS case and four controls who had rs3849942 A/A genotype but no intermediatelength allele ( $p=0.51$ Fisher's test). Additional file 1: Supplementary Table 4 shows the distribution of rs3849942 (A) in carriers of each intermediate-length allele in ALS patients and controls. Practically all intermediatelength allele carriers with $\geq 17$ repeats were also carriers of rs3849942 (A) in ALS cases and controls (with one exception among the 76 controls with $\geq 17$ repeats and rs3849942 data available).

Table 1 C9orf72 hexanucleotide repeat intermediatelength allele carriers in 525 ALS patients and 3950 controls after exclusion of expansion carriers

\begin{tabular}{lcclll}
\hline Longer allele & Controls $\mathbf{n}$ & ALS $\mathbf{n}$ & $\boldsymbol{p}$ & OR & $\mathbf{9 5 \%} \mathbf{C l}$ \\
\hline $7-45$ & $1293(33 \%)$ & $185(35 \%)$ & 0.26 & 1.12 & $0.92-1.36$ \\
$17-45$ & $101(2.6 \%)$ & $19(3.6 \%)$ & 0.15 & 1.43 & $0.82-2.74$ \\
$21-45$ & $66(1.7 \%)$ & $12(2.3 \%)$ & 0.29 & 1.38 & $0.67-2.59$ \\
$24-45$ & $43(1.1 \%)$ & $6(1.1 \%)$ & 0.82 & 1.05 & $0.36-2.50$ \\
$24-30$ & $30(0.76 \%)$ & $3(0.57 \%)$ & 1 & 0.75 & $0.15-2.43$ \\
\hline
\end{tabular}


Table 2 Individuals with two intermediate-length alleles in 525 ALS patients and 3950 controls after exclusion of expansion carriers

\begin{tabular}{|c|c|c|c|c|c|}
\hline Shorter/longer allele & Controls n (\%) & ALS n (\%) & $p$ & OR & $95 \% \mathrm{Cl}$ \\
\hline$\geq 7 / \geq 7$ & $104(2.6 \%)$ & $26(5.0 \%)$ & 0.005 & 1.93 & $1.19-3.02$ \\
\hline $7-16 / 7-16$ & 94 (2.4\%) & $19(3.6 \%)$ & 0.098 & 1.57 & $0.90-2.62$ \\
\hline$\geq 7 / 17-45$ & $10(0.25 \%)$ & $7(1.3 \%)$ & 0.0020 & 5.32 & $1.71-15.56$ \\
\hline$\geq 7 / 21-45$ & $3(0.076 \%)$ & $6(1.1 \%)$ & 0.00016 & 15.19 & $3.23-94.21$ \\
\hline$\geq 7 / 24-45$ & $1(0.025 \%)$ & $4(0.76 \%)$ & 0.00085 & 30.26 & $2.99-1479$ \\
\hline
\end{tabular}

Table 3 Comparison of rs3849942 genotypes in 505 ALS cases and 3172 controls after the exclusion of expansion carriers

\begin{tabular}{llll}
\hline $\begin{array}{l}\text { rs3849942 } \\
\text { genotype }\end{array}$ & Controls $\mathbf{n}(\%)$ & ALS $\mathbf{n}(\%)$ & $\mathbf{x}^{\mathbf{2}}$ \\
\hline G/G & $2177(68.6 \%)$ & $323(64.0 \%)$ & 1.40 \\
G/A & $910(28.7 \%)$ & $157(31 \%)$ & 0.87 \\
A/A & $85(2.7 \%)$ & $25(5.0 \%)$ & 7.51 \\
Total & 3172 & 505 & $9.77,2 \mathrm{df}$, \\
& & & $p=0.0076$ \\
\hline
\end{tabular}

C9orf72 hexanucleotide repeat intermediate-length allele distributions in different age groups

To test for a possible effect on survival presenting as a difference in the frequency of intermediate-length allele carriers in different age groups, we divided the controls into three age categories $18-65,66-84$ and $85-106$ years. We did not observe a statistically significant linear trend between the proportion of intermediate-length allele carriers and age groups (Table 4).

We did not have the power to detect differences in carriers of two copies of intermediate-length alleles due to their rarity but analyzed them for descriptive purposes. This analysis showed that in the oldest age group ( $\geq 85$ years) there were no individuals with two intermediate-length alleles where the longer allele was $\geq 21$ repeats. The C9orf72 haplotype tagging SNP rs3849942 homozygosity (A/A) was found in 16/436 (3.7\%), 43/1688 (2.5\%) and $26 / 1047(2.5 \%)$ in the age groups 18-65, $66-84$ and $\geq 85$ years respectively $(p=, 0.28$ CochranArmitage trend test).

\section{Discussion}

In our analyses, the frequencies of the C9orf72 hexanucleotide repeat intermediate-length allele carriers did not show a statistically significant difference between Finnish ALS patients and controls when only the longer allele was considered (all $p \geq 0.15$ ). In addition, we did not observe any significant differences in the frequency of carriers of the intermediate-length alleles in controls belonging to
Table 4 Intermediate repeat length allele frequencies in different age groups of controls

\begin{tabular}{|c|c|c|c|c|}
\hline & $18-65$ years & $66-84$ years & 85-105 years & $p$ value $^{a}$ \\
\hline \multicolumn{5}{|l|}{ Longer allele } \\
\hline $7-45$ & $273(31 \%)$ & $656(33 \%)$ & $363(33 \%)$ & 0.46 \\
\hline $17-45$ & $29(3.3 \%)$ & $44(2.2 \%)$ & $28(2.5 \%)$ & 0.33 \\
\hline $21-45$ & $18(2.1 \%)$ & $29(1.5 \%)$ & $19(1.7 \%)$ & 0.62 \\
\hline $24-45$ & $12(1.4 \%)$ & $17(0.86 \%)$ & $14(1.3 \%)$ & 0.92 \\
\hline $24-30$ & $10(1.1 \%)$ & $9(0.46 \%)$ & $11(1.0 \%)$ & 0.85 \\
\hline Two 7-45 alleles & $26(3.0 \%)$ & $51(2.6 \%)$ & $27(2.5 \%)$ & 0.48 \\
\hline \multicolumn{5}{|c|}{ Longer allele in individuals with two 7-45 alleles } \\
\hline $7-16$ & $23(2.6 \%)$ & $47(2.4 \%)$ & $24(2.2 \%)$ & \\
\hline$\geq 17$ & $3(0.34 \%)$ & $4(0.20 \%)$ & $3(0.27 \%)$ & \\
\hline$\geq 21$ & $1(0.11 \%)$ & $2(0.10 \%)$ & 0 & \\
\hline$\geq 24$ & 0 & $1(0.050 \%)$ & 0 & \\
\hline $\mathrm{N}$ of age group & 873 & 1973 & 1102 & \\
\hline
\end{tabular}

a Cochran-Armitage trend test. Excluded 10 individuals from whom age group was unknown

different age groups (Table 3) suggesting that carriership of these alleles are not subject to strong negative selection during aging. Hence, just carriership of an intermediate-length allele does not confer increased risk of ALS or play a major role in survival in the Finnish population.

However, when individuals with two copies of the intermediate-length alleles were studied, significant associations were found, especially when the longer allele was $\geq 17$ repeats (Table 2 ). The highest homozygous number of repeats was 12 repeats (Additional file 1: Supplementary Table 5) indicating that most of the risk genotypes were compound heterozygotes. Compound heterozygote effect of the intermediate-length CAG-repeat alleles has been previously shown in spinocerebellar ataxia 3 [22]. The "two copy effect" was further supported by the association of the risk haplotype marker homozygosity with ALS (Table 3).

Our results suggest that in the Finnish population, carrying one intermediate-length allele does not significantly increase the risk of ALS but having two such alleles and one of these $\geq 17$ repeats raises the odds of ALS about 
fivefold. This is not a big increase in risk in a rare disease like ALS with a lifetime risk of ca. 1/400. Therefore, in ALS patients with two intermediate-length alleles, the effect of additional genetic or environmental factors is likely important for the disease development. It is of note, that one of our ALS patients who had 8/36 repeat alleles was also homozygous for the $S O D 1 * D 91 A$ mutation and survived 14 years after diagnosis. Such a long survival is typical in SOD1*D91A ALS but not in C9orf72 ALS suggesting that the major genetic factor modulating the clinical picture was the $S O D 1$ mutation.

Our results agree with a previous study that reported in Belgian ALS and FTD-ALS patients $(n=135)$ a significantly increased risk in carriers of two copies of the intermediatelength alleles (OR 2.08, $p=0.04$ ) [9]. Also, in a FlandersBelgian cohort of patients with FTD (without C9orf72 expansion) a significant risk for homozygous carriers of the C9orf72 risk haplotype tagging SNP was found (OR 1.75, $p=0.04$ ), which disappeared after removal of intermediatelength allele carriers [24]. Functionally the intermediatelength alleles have been shown to modulate expression of C9orf72, which may vary in different tissues $[3,9]$. In nerve tissue the intermediate-length alleles and the risk haplotype tagging SNP have been shown to result in increased C9orf72 transcription from the promoter upstream of the hexanucleotide repeat, while intermediate alleles did not generate RNA foci or dipeptide repeat proteins that are pathognomonic for the C9orf72 expansion [3].

Our results are somewhat in contrast with a recent meta-analysis comprising 5071 ALS cases and 3747 controls that reported an association of 24-30 repeat alleles with ALS with an odds ratio 4.20 (random-effects model $p=0.02$ ) [12]. The association with 24-30 repeats was robust and the association was observed even when omitting one study at a time in the meta-analysis. Another report suggesting the pathogenicity of alleles of $\geq 17$ repeats studied autopsy-proven corticobasal degeneration cases (CBD) from UK and USA versus global controls [3]. These intermediate-length alleles also increased C9orf72 expression in the human brain and in neural progenitor cells [3]. Complete genotypes were not reported in the ALS meta-analysis, while in the CBD study 2 out of 13 cases were compound heterozygotes for an intermediate-length allele. In both studies, it was assumed that carriership of either $24-30$ repeats (ALS) or $\geq 17$ repeats (CBD) was the main risk factor for disease. Our data does not support this assumption to be true in Finland. There are several potential explanations for our different results.

First, the genetics and penetrance of the intermediate-length alleles might be different in Finland versus other populations. All carriers of intermediate-length alleles of $\geq 17$ repeats were also carriers of the risk haplotype-tagging SNP (with only one exception, Additional file 1: Supplementary Table 5), which indicates that the gross haplotype background is similar in Finland and other populations. However, there could be a protective factor in Finland that decreases the risk of heterozygotes and allows the carrier frequencies to rise in normal population. It is of note that two copies of the intermediate-length alleles were required for increased risk in Belgian ALS and FTD-ALS patients, too [9]. Hence, the hypothetical protective factor should be widely spread in Europe.

Second, population stratification can confound the analyses. The observed ethnic and geographic differences in the intermediate-length allele frequencies $[12,13]$ may potentially result in spurious associations due to population stratification. The discrepancy between our results and previous reports seem to be largely driven by the higher frequency of the long intermediate-length alleles $(\geq 20$ repeats) in our Finnish controls. The frequencies of the long intermediate-length alleles in ALS and CBD cases show much less dispersion than controls between populations as illustrated in Fig. 1. Therefore, studies using multinational cohorts need to carefully account for population stratification and, additionally, use sufficiently large subcohorts to ensure that rare alleles can be captured.

Third, different genotyping methodology of the C9orf72 hexanucleotide repeat can affect results. It is well-known that genotyping of the C9orf72 hexanucleotide repeat can be challenging, as the large size and high GC content of the C9orf72 expansion does not allow full polymerization during PCR. Even accredited laboratories report different genotypes from the same sample [6]. For differentiating homozygotes and heterozygotes in unclear samples, we used an additional confirmatory PCR method (Additional file 1: Supplementary Figure 1). There may also be slight inconsistencies in the determination of the exact lengths of the longer alleles (e.g. 23 vs. 24 repeats) with RP-PCR. For this reason in our analyses the smallest range of repeat length was seven (24-30 repeats). Meta-analyses rely on previous studies often with varying genotyping methodologies, which can make the harmonization of data difficult. The different sources of DNA is another possible confounding factor, as the use of blood versus brain or lymphoblastoid cell line derived DNA may cause significant bias [2, 8] although not yet systematically studied in C9orf72 intermediate-length alleles. Huntington's disease CAG-repeat represents a case in which the size of an intermediate allele with 34 repeats has been shown to increase in serially passaged lymphoblastoid cell lines [4]. 


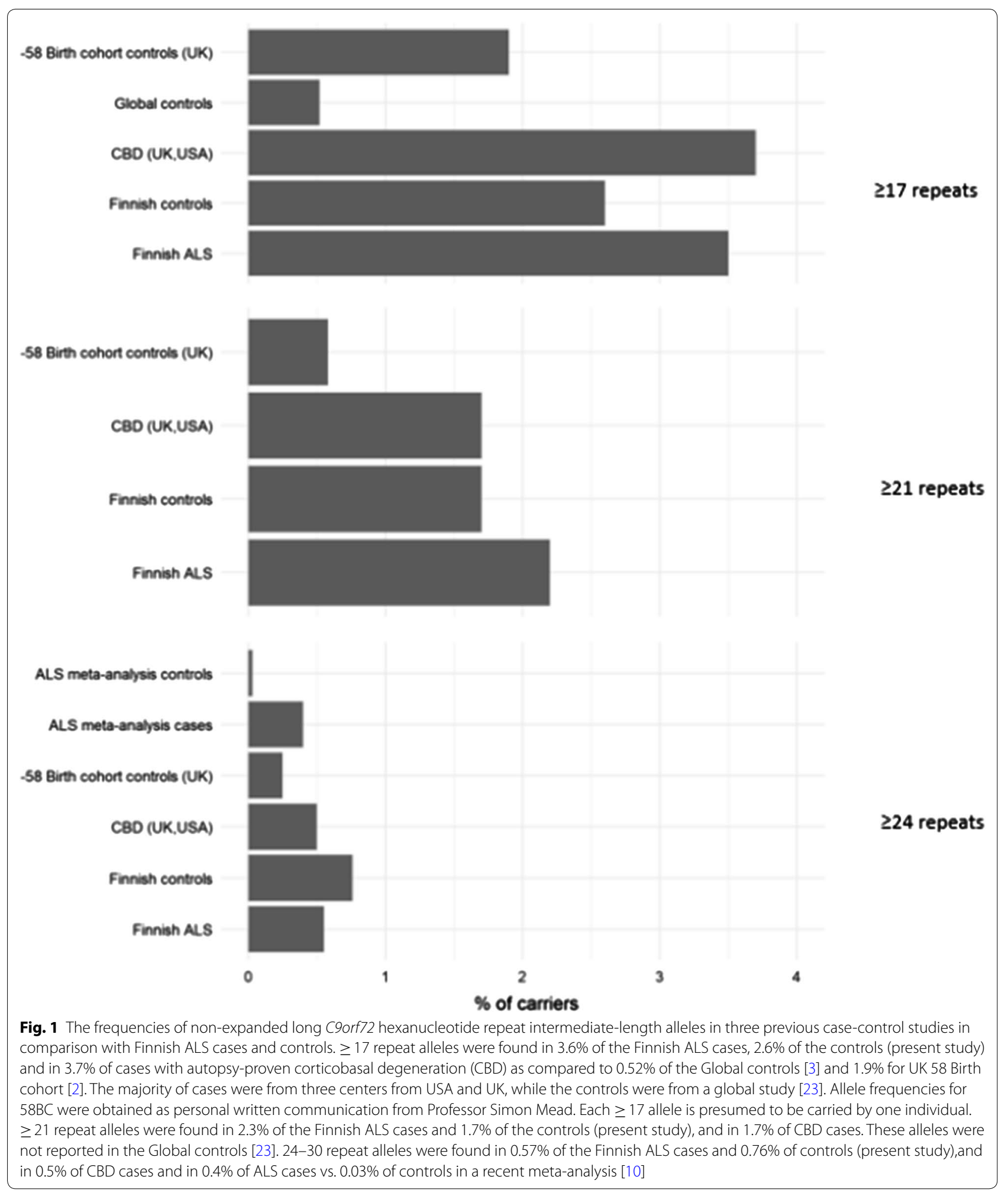

Our study's strength is the focus on Finnish individuals, which decreases the effects of population stratification and allows a sufficiently large number of longer intermediate-length allele carriers for comparisons because these alleles are relatively common in this population [13]. However, it also affects the generalizability of 
our results. Based on our assessment of $C 9$ orf 72 repeat length Finns have more 2-6 repeat alleles, less 7-19 repeat alleles and again more $\geq 20$ repeat alleles than the general European population. The risk haplotype (and intermediate-length allele) tagging rs3849942 (A) is less common in Finland as compared to non-Finnish Europeans and reflects the lower frequency of the 7-19 repeat alleles in Finns. Therefore, we cannot exclude the possibility of unknown selection factors facilitating the enrichment of $\geq 20$ alleles in the Finnish population.

Our study has also limitations. The controls and ALS cases were genotyped for rs3849942 using different platforms and different genotyping centers, which can lead to slight differences in allele frequencies. However, we do not believe this to be an important source of error, since the allele frequencies in our controls were consistent with the Finnish samples of the gnomAD database v.3 [14]. Moreover, we had whole-genome sequencing data on ca. 300 ALS cases that had also been genotyped for rs3849942 and the concordance of genotypes was $100 \%$. Furthermore, RP-PCR, which we used to assess C9orf72 repeat lengths, is accurate in detecting expansions and sizing most alleles, but like with other genotyping methods, the longer the allele, the harder it is to assess the exact length. Given that rs3849942 genotypes and the C9orf72 repeat lengths correlated well, the number of wrongly assessed genotypes is likely small, and should not affect the conclusions of the study. We genotyped all cohorts except one from peripheral blood-derived DNA and age of the DNA samples varied. The cohort with saliva-derived DNA had the lowest genotyping success rate (97.2\% vs. 98.9-99.4\% in other cohorts), but the genotype distribution did not differ significantly from the other cohorts suggesting that the different source of DNA should not cause meaningful bias to the results. On the other hand, although we did not observe any marked difference in the C9orf72 allele distribution of our younger and older control individuals, we cannot exclude small effects on survival, undetectable with the present sample size. A larger study is required to analyze small effects on survival and to test also survival in carriers of two copies of intermediate-length alleles and homozygotes for the C9orf72 risk haplotype tagging SNPs.

\section{Conclusions}

Our data indicate that the C9orf72 intermediate-length alleles increase the risk of ALS when present in two copies, carriership of only one intermediate-length allele is not associated with ALS or survival in the Finnish population. The clinical significance of the intermediatelength alleles should be critically re-assessed in carriers of one and two copies of these alleles.

\section{Supplementary information}

Supplementary information accompanies this paper at https://doi. org/10.1186/s40478-020-01059-5.

Additional file 1 Power calculations and detailed genotyping information.

\section{Abbreviations \\ ALS: amyotrophic lateral sclerosis; CBD: corticobasal degeneration; CI 95\%: 95\% confidence interval; FTD: frontotemporal dementia; HBS: Helsinki Businessmen study; HBSC: Helsinki Birth cohort study; MAF: minor allele frequency; OR: odds ratio; RP-PCR: repeat-primed PCR.}

\section{Acknowledgements}

We would like to thank all participants of this study. We wish to express our gratitude to Bryan J. Traynor for insightful comments on the manuscript and Simon Mead for sharing genotyping data. We thank the FinnGen research project for rs3849942 genotype data of the ALS cases.

\section{Authors' contributions}

KK, PJT: study design; HL, PJT, JL, A-KN, KM, JGE, JL, TS: patient and control recruitment; KK, LJ, SJS, JL, JGE, TS: genotyping; KK, SJS, PJT: statistical analyses; all authors: drafting and reviewing of manuscript. All authors read and approved the final manuscript.

\section{Funding \\ This study was funded by the Finnish Cultural Foundation, the Paulo Founda- tion and The Finnish Brain Foundation sr, the Sigrid Juselius Foundation, Helsinki University Hospital grants (TYH2018213, TYH2019254), ALS tuttu ry and the Finnish Academy (318868)}

\section{Availability of data and materials}

The datasets used and/or analysed during the current study available from the corresponding author on reasonable request.

\section{Ethics approval and consent to participate}

The study was approved by the Ethics Committee of the Helsinki University Central Hospital (diary number 401/13/03/01/09 and HUS/1720/2019). All individuals or their next-of-kin gave a written informed consent.

\section{Consent for publication}

Not applicable.

\section{Competing interests}

Pentti J. Tienari holds a patent on C9orf72 in diagnostics and treatment of ALS/FTD. Other authors declare that they have no competing interests.

\footnotetext{
Author details

${ }^{1}$ Translational Immunology, Research Programs Unit, University of Helsinki, Helsinki, Finland. ${ }^{2}$ Department of Neurology, Helsinki University Hospital, P.O. Box 63, 00014 Helsinki, Finland. ${ }^{3}$ Department of Psychology and Logopedics, University of Helsinki, P.O. Box 21, 00014 Helsinki, Finland. ${ }^{4}$ Research Unit of Clinical Neuroscience, Neurology, University of Oulu, P.O. Box 5000, 90014 Oulu, Finland. ${ }^{5}$ Department of Neurology and Medical Research Center, Oulu University Hospital, Oulu, Finland. ${ }^{6}$ Division of Neonatology, Rady Children's Hospital San Diego, University of California San Diego, San Diego, CA, USA. ${ }^{7}$ Department of Obstetrics \& Gynaecology and Human Potential Translational Research Programme, Yong Loo Lin School of Medicine, National University of Singapore and Singapore Institute for Clinical Sciences, Agency for Science, Technology and Research (A*STAR), Singapore, Singapore. ${ }^{8}$ Department of General Practice and Primary Health Care, University of Helsinki and Helsinki University Hospital, Helsinki, Finland. ${ }^{9}$ Folkhälsan Research Center, Helsinki, Finland. ${ }^{10}$ Center for Life Course Health Research/Geriatrics, University of Oulu, Oulu, Finland. ${ }^{11}$ Department of Medicine, Geriatric Clinic, University of Helsinki, Helsinki University Central Hospital, Helsinki, Finland.
} 
Received: 12 July 2020 Accepted: 14 October 2020

Published online: 09 November 2020

\section{References}

1. Anderson CA, Pettersson FH, Clarke GM, Cardon LR, Morris AP, Zondervan KT (2010) Data quality control in genetic case-control association studies. Nat Protoc 5:1564-1573. https://doi.org/10.1038/nprot.2010.116

2. Beck J, Poulter M, Hensman D, Rohrer JD, Mahoney CJ, Adamson G, Campbell T, Uphill J, Borg A, Fratta P, Orrell RW, Malaspina A, Rowe J, Brown J, Hodges J, Sidle K, Polke JM, Houlden H, Schott JM, Fox NC, Rossor MN, Tabrizi SJ, Isaacs AM, Hardy J, Warren JD, Collinge J, Mead S (2013) Large C9orf72 hexanucleotide repeat expansions are seen in multiple neurodegenerative syndromes and are more frequent than expected in the UK population. Am J Hum Genet 92:345-353. https://doi. org/10.1016/j.ajhg.2013.01.011

3. Cali CP, Patino M, Tai YK, Ho WY, McLean CA, Morris CM, Seeley WW, Miller BL, Gaig C, Vonsattel JPG, White CL, Roeber S, Kretzschmar H, Troncoso JC, Troakes C, Gearing M, Ghetti B, Van Deerlin VM, Lee VM, Trojanowski JQ, Mok KY, Ling H, Dickson DW, Schellenberg GD, Ling SC, Lee EB (2019) C9orf72 intermediate repeats are associated with corticobasal degeneration, increased C9orf72 expression and disruption of autophagy. Acta Neuropathol 138:795-811. https://doi.org/10.1007/s00401-019-02045-5

4. Cannella M, Maglione V, Martino T, Simonelli M, Ragona G, Squitieri F (2005) New Huntington disease mutation arising from a paternal CAG34 allele showing somatic length variation in serially passaged lymphoblasts. Am J Med Genet B Neuropsychiatr Genet 133B:127-130. https:// doi.org/10.1002/ajmg.b.30125

5. Chen Y, Lin Z, Chen X, Cao B, Wei Q, Ou R, Zhao B, Song W, Wu Y, Shang HF (2016) Large C9orf72 repeat expansions are seen in Chinese patients with sporadic amyotrophic lateral sclerosis. Neurobiol Aging 38:217.e15-217. e22. https://doi.org/10.1016/j.neurobiolaging.2015.11.016

6. Crook A, McEwen A, Fifita JA, Zhang K, Kwok JB, Halliday G, Blair IP, Rowe DB (2019) The C9orf72 hexanucleotide repeat expansion presents a challenge for testing laboratories and genetic counseling. Amyotroph Lateral Scler Frontotemporal Degener 20:310-316. https://doi. org/10.1080/21678421.2019.1588904

7. DeJesus-Hernandez M, Mackenzie IR, Boeve BF, Boxer AL, Baker M, Rutherford NJ, Nicholson AM, Finch NA, Flynn H, Adamson J, Kouri N, Wojtas A, Sengdy P, Hsiung GY, Karydas A, Seeley WW, Josephs KA, Coppola G, Geschwind DH, Wszolek ZK, Feldman H, Knopman DS, Petersen RC, Miller BL, Dickson DW, Boylan KB, Graff-Radford NR, Rademakers R (2011) Expanded GGGGCC hexanucleotide repeat in noncoding region of C9ORF72 causes chromosome 9p-linked FTD and ALS. Neuron 72:245-256. https://doi.org/10.1016/j.neuron.2011.09.011

8. Fratta P, Polke JM, Newcombe J, Mizielinska S, Lashley T, Poulter M, Beck J, Preza E, Devoy A, Sidle K, Howard R, Malaspina A, Orrell RW, Clarke J, Lu CH, Mok K, Collins T, Shoaii M, Nanji T, Wray S, Adamson G, Pittman A, Renton AE, Traynor BJ, Sweeney MG, Revesz T, Houlden H, Mead S, Isaacs AM, Fisher EM (2015) Screening a UK amyotrophic lateral sclerosis cohort provides evidence of multiple origins of the C9orf72 expansion. Neurobiol Aging 36:546.e1-546.e7. https://doi.org/10.1016/j.neurobiola ging.2014.07.037

9. Gijselinck I, Van Mossevelde S, van der Zee J, Sieben A, Engelborghs S, De Bleecker J, Ivanoiu A, Deryck O, Edbauer D, Zhang M, Heeman B, Baumer V, Van den Broeck M, Mattheijssens M, Peeters K, Rogaeva E, De Jonghe P, Cras P, Martin JJ, de Deyn PP, Cruts M, Van Broeckhoven C (2016) The C9orf72 repeat size correlates with onset age of disease, DNA methylation and transcriptional downregulation of the promoter. Mol Psychiatry 21:1112-1124. https://doi.org/10.1038/mp.2015.159

10. Gomez-Tortosa E, Gallego J, Guerrero-Lopez R, Marcos A, Gil-Neciga E, Sainz MJ, Diaz A, Franco-Macias E, Trujillo-Tiebas MJ, Ayuso C, Perez-Perez $J$ (2013) C9ORF72 hexanucleotide expansions of 20-22 repeats are associated with frontotemporal deterioration. Neurology 80:366-370. https:// doi.org/10.1212/WNL.0b013e31827f08ea

11. Hokkanen L, Launes J, Michelsson K (2013) The Perinatal Adverse events and Special Trends in Cognitive Trajectory (PLASTICITY) - pre-protocol for a prospective longitudinal follow-up cohort study. F1000Res 2:50-50.v1. https://doi.org/10.12688/f1000research.2-50.v1
12. lacoangeli A, Al Khleifat A, Jones AR, Sproviero W, Shatunov A, OpieMartin S, Initiative Alzheimer's Disease Neuroimaging, Morrison KE, Shaw PJ, Shaw CE, Fogh I, Dobson RJ, Newhouse SJ, Al-Chalabi A (2019) C9orf72 intermediate expansions of 24-30 repeats are associated with ALS. Acta Neuropathol Commun 7:115. https://doi.org/10.1186/s40478-019-0724-4

13. Kaivola K, Kiviharju A, Jansson L, Rantalainen V, Eriksson JG, Strandberg TE, Laaksovirta H, Renton AE, Traynor BJ, Myllykangas L, Tienari PJ (2019) C9orf72 hexanucleotide repeat length in older population: normal variation and effects on cognition. Neurobiol Aging 84:242.e7-242.e12. https ://doi.org/10.1016/j.neurobiolaging.2019.02.026

14. Karczewski KJ, Francioli LC, Tiao G, Cummings BB, Alfoldi J, Wang Q, Collins RL, Laricchia KM, Ganna A, Birnbaum DP, Gauthier LD, Brand H, Solomonson M, Watts NA, Rhodes D, Singer-Berk M, England EM, Seaby EG, Kosmicki JA, Walters RK, Tashman K, Farjoun Y, Banks E, Poterba T, Wang A, Seed C, Whiffin N, Chong JX, Samocha KE, Pierce-Hoffman E, Zappala Z, O'Donnell-Luria AH, Minikel EV, Weisburd B, Lek M, Ware JS, Vittal C, Armean IM, Bergelson L, Cibulskis K, Connolly KM, Covarrubias M, Donnelly S, Ferriera S, Gabriel S, Gentry J, Gupta N, Jeandet T, Kaplan D, Llanwarne C, Munshi R, Novod S, Petrillo N, Roazen D, Ruano-Rubio V, Saltzman A, Schleicher M, Soto J, Tibbetts K, Tolonen C, Wade G, Talkowski ME, Genome Aggregation Database Consortium, Neale BM, Daly MJ, MacArthur DG (2020) The mutational constraint spectrum quantified from variation in 141,456 humans. Nature 581:434-443. https://doi. org/10.1038/s41586-020-2308-7

15. Laaksovirta H, Peuralinna T, Schymick JC, Scholz SW, Lai SL, Myllykangas L, Sulkava R, Jansson L, Hernandez DG, Gibbs JR, Nalls MA, Heckerman D, Tienari PJ, Traynor BJ (2010) Chromosome 9p21 in amyotrophic lateral sclerosis in Finland: a genome-wide association study. Lancet Neurol 9:978-985. https://doi.org/10.1016/S1474-4422(10)70184-8

16. Majounie E, Renton AE, Mok K, Dopper EG, Waite A, Rollinson S, Chio A, Restagno G, Nicolaou N, Simon-Sanchez J, van Swieten JC, Abramzon Y, Johnson JO, Sendtner M, Pamphlett R, Orrell RW, Mead S, Sidle KC, Houlden H, Rohrer JD, Morrison KE, Pall H, Talbot K, Ansorge O, Chromosome 9-ALS/FTD Consortium, French research network on, FTLD/FTLD/ALS, ITALSGEN Consortium, Hernandez DG, Arepalli S, Sabatelli M, Mora G, Corbo M, Giannini F, Calvo A, Englund E, Borghero G, Floris GL, Remes AM, Laaksovirta H, McCluskey L, Trojanowski JQ, Van Deerlin VM, Schellenberg GD, Nalls MA, Drory VE, Lu CS, Yeh TH, Ishiura H, Takahashi Y, Tsuji S, Le Ber I, Brice A, Drepper C, Williams N, Kirby J, Shaw P, Hardy J, Tienari PJ, Heutink P, Morris HR, Pickering-Brown S, Traynor BJ (2012) Frequency of the C9orf72 hexanucleotide repeat expansion in patients with amyotrophic lateral sclerosis and frontotemporal dementia: a cross-sectional study. Lancet Neurol 11:323-330. https://doi.org/10.1016/S1474-4422(12)70043 $-1$

17. Meinila M, Finnila S, Majamaa K (2001) Evidence for mtDNA admixture between the Finns and the Saami. Hum Hered 52:160-170. https://doi. org/10.1159/000053372

18. Ng ASL, Tan EK (2017) Intermediate C9orf72 alleles in neurological disorders: does size really matter? J Med Genet 54:591-597. https://doi. org/10.1136/jmedgenet-2017-104752

19. Niemi AK, Hervonen A, Hurme M, Karhunen PJ, Jylha M, Majamaa K (2003) Mitochondrial DNA polymorphisms associated with longevity in a Finnish population. Hum Genet 112:29-33. https://doi.org/10.1007/s0043 9-002-0843-y

20. Nuytemans K, Bademci G, Kohli MM, Beecham GW, Wang L, Young Jl, Nahab F, Martin ER, Gilbert JR, Benatar M, Haines JL, Scott WK, Zuchner S, Pericak-Vance MA, Vance JM (2013) C9ORF72 intermediate repeat copies are a significant risk factor for Parkinson disease. Ann Hum Genet 77:351-363. https://doi.org/10.1111/ahg.12033

21. Renton AE, Majounie E, Waite A, Simon-Sanchez J, Rollinson S, Gibbs JR, Schymick JC, Laaksovirta H, van Swieten JC, Myllykangas L, Kalimo H, Paetau A, Abramzon Y, Remes AM, Kaganovich A, Scholz SW, Duckworth J, Ding J, Harmer DW, Hernandez DG, Johnson JO, Mok K, Ryten M, Trabzuni D, Guerreiro RJ, Orrell RW, Neal J, Murray A, Pearson J, Jansen IE, Sondervan D, Seelaar H, Blake D, Young K, Halliwell N, Callister JB, Toulson G, Richardson A, Gerhard A, Snowden J, Mann D, Neary D, Nalls MA, Peuralinna T, Jansson L, Isoviita VM, Kaivorinne AL, Holtta-Vuori M, Ikonen E, Sulkava R, Benatar M, Wuu J, Chio A, Restagno G, Borghero G, Sabatelli M, ITALSGEN Consortium, Heckerman D, Rogaeva E, Zinman L, Rothstein JD, Sendtner M, Drepper C, Eichler EE, Alkan C, Abdullaev Z, Pack SD, Dutra A, Pak E, Hardy J, Singleton A, Williams NM, Heutink P, Pickering-Brown S, 
Morris HR, Tienari PJ, Traynor BJ (2011) A hexanucleotide repeat expansion in C9ORF72 is the cause of chromosome 9p21-linked ALS-FTD. Neuron 72:257-268. https://doi.org/10.1016/j.neuron.2011.09.010

22. Takahashi Y, Kanai M, Taminato T, Watanabe S, Matsumoto C, Araki T, Okamoto T, Ogawa M, Murata M (2016) Compound heterozygous intermediate MJD alleles cause cerebellar ataxia with sensory neuropathy. Neurol Genet 3:e123. https://doi.org/10.1212/NXG.0000000000000123

23. Theuns J, Verstraeten A, Sleegers K, Wauters E, Gijselinck I, Smolders S, Crosiers D, Corsmit E, Elinck E, Sharma M, Kruger R, Lesage S, Brice A, Chung SJ, Kim MJ, Kim YJ, Ross OA, Wszolek ZK, Rogaeva E, Xi Z, Lang AE, Klein C, Weissbach A, Mellick GD, Silburn PA, Hadjigeorgiou GM, Dardiotis E, Hattori N, Ogaki K, Tan EK, Zhao Y, Aasly J, Valente EM, Petrucci S, Annesi G, Quattrone A, Ferrarese C, Brighina L, Deutschlander A, Puschmann A, Nilsson C, Garraux G, LeDoux MS, Pfeiffer RF, Boczarska-Jedynak M, Opala G, Maraganore DM, Engelborghs S, De Deyn PP, Cras P, Cruts M, Van Broeckhoven C, GEO-PD Consortium (2014) Global investigation and meta-analysis of the C9orf72 (G4C2)n repeat in Parkinson disease. Neurology 83:1906-1913. https://doi.org/10.1212/WNL.00000000000001012

24. van der Zee J, Gijselinck I, Dillen L, Van Langenhove T, Theuns J, Engelborghs S, Philtjens S, Vandenbulcke M, Sleegers K, Sieben A, Baumer V, Maes G, Corsmit E, Borroni B, Padovani A, Archetti S, Perneczky R, Diehl-Schmid J, de Mendonca A, Miltenberger-Miltenyi G, Pereira S, Pimentel J, Nacmias B, Bagnoli S, Sorbi S, Graff C, Chiang HH, Westerlund M, Sanchez-Valle R, Llado A, Gelpi E, Santana I, Almeida MR, Santiago B, Frisoni G, Zanetti O, Bonvicini C, Synofzik M, Maetzler W, Vom Hagen JM, Schols L, Heneka MT, Jessen F, Matej R, Parobkova E, Kovacs GG, Strobel T, Sarafov S, Tournev I, Jordanova A, Danek A, Arzberger T, Fabrizi GM, Testi S, Salmon E, Santens P, Martin JJ, Cras P, Vandenberghe R, De Deyn PP, Cruts M, Van Broeckhoven C, van der Zee J, Gijselinck I, Dillen L, Van Langenhove T, Theuns J, Philtjens S, Sleegers K, Baumer V, Maes
G, Corsmit E, Cruts M, Van Broeckhoven C, van der Zee J, Gijselinck I, Dillen L, Van Langenhove T, Philtjens S, Theuns J, Sleegers K, Baumer V, Maes G, Cruts M, Van Broeckhoven C, Engelborghs S, De Deyn PP, Cras P, Engelborghs S, De Deyn PP, Vandenbulcke M, Vandenbulcke M, Borroni B, Padovani A, Archetti S, Perneczky R, Diehl-Schmid J, Synofzik M, Maetzler W, Muller Vom Hagen J, Schols L, Synofzik M, Maetzler W, Muller Vom Hagen J, Schols L, Heneka MT, Jessen F, Ramirez A, Kurzwelly D, Sachtleben C, Mairer W, de Mendonca A, Miltenberger-Miltenyi G, Pereira S, Firmo C, Pimentel J, Sanchez-Valle R, Llado A, Antonell A, Molinuevo J, Gelpi E, Graff C, Chiang HH, Westerlund M, Graff C, Kinhult Stahlbom A, Thonberg H, Nennesmo I, Borjesson-Hanson A, Nacmias B, Bagnoli S, Sorbi S, Bessi V, Piaceri I, Santana I, Santiago B, Santana I, Helena Ribeiro M, Rosario Almeida M, Oliveira C, Massano J, Garret C, Pires P, Frisoni G, Zanetti O, Bonvicini C, Sarafov S, Tournev I, Jordanova A, Tournev I, Kovacs GG, Strobel T, Heneka MT, Jessen F, Ramirez A, Kurzwelly D, Sachtleben C, Mairer W, Jessen F, Matej R, Parobkova E, Danel A, Arzberger T, Maria Fabrizi G, Testi S, Ferrari S, Cavallaro T, Salmon E, Santens P, Cras P, European Early-Onset Dementia Consortium (2013) A pan-European study of the C9orf72 repeat associated with FTLD: geographic prevalence, genomic instability, and intermediate repeats. Hum Mutat 34:363-373. https://doi. org/10.1002/humu.22244

25. Van Mossevelde S, van der Zee J, Cruts M, Van Broeckhoven C (2017) Relationship between C9orf72 repeat size and clinical phenotype. Curr Opin Genet Dev 44:117-124. https://doi.org/10.1016/j.gde.2017.02.008

\section{Publisher's Note}

Springer Nature remains neutral with regard to jurisdictional claims in published maps and institutional affiliations.
Ready to submit your research? Choose BMC and benefit from:

- fast, convenient online submission

- thorough peer review by experienced researchers in your field

- rapid publication on acceptance

- support for research data, including large and complex data types

- gold Open Access which fosters wider collaboration and increased citations

- maximum visibility for your research: over 100M website views per year

At BMC, research is always in progress.

Learn more biomedcentral.com/submissions 